\title{
ENTRE EL INFIERNO Y EL CIELO: DOS OBRAS DE LA NARRATIVA \\ CHILENA EN 1904
}

\author{
POR \\ JUAN DURÁN LuZIo \\ Universidad Nacional, Costa Rica
}

En 1904 se publican en puntos geográficos muy distantes dos obras de autores nacionales que estaban llamadas a cierta polémica celebridad; en Santiago un autor primerizo y casi desconocido, Baldomero Lillo, da a conocer un volumen de ocho cuentos bajo el curioso título de Sub terra. De los ocho relatos allí incluidos, siete se desarrollan en torno a un tema central: la existencia miserable de los mineros del carbón en los alrededores de Lota, en el sur de Chile; el último de la colección es prácticamente el único que ocurre sobre la superficie de la tierra, relativo a un instante de frustración en la vida de un viejo peón campesino. ${ }^{1}$

Por su parte en París un autor ya consagrado, Alberto Blest Gana, ve aparecer bajo el sello de la reconocida casa editorial de Garnier Hermanos su quinta novela, Los trasplantados. El título alude a la situación regalada y ostentosa de unos pocos chilenos en las altas esferas del París de moda, donde a pesar de su origen criollo, llevan una activa vida social, que luego de muchos empeños, los conduce hasta los círculos bastante exclusivos de la nobleza europea, todo lo cual constituye el asunto de la obra. ${ }^{2}$

$\mathrm{El}$ primero de ambos autores es un joven de la clase media pobre de las provincias, quien vive de atender un almacén cercano a las minas de carbón de Lota, donde a diario oye del durísimo pasar de sus clientes; el segundo, es el anciano y respetado ex-embajador de Chile en Francia, miembro del Olimpo nacional por nacimiento y vinculado al alto mundo de París gracias a su cargo y a su calidad de decano de los diplomáticos latinoamericanos allí acreditados.

En los cuentos de Sub terra hay varias menciones a la mina como un mundo subterráneo oscuro y saturado de vapores irrespirables, como a una prisión para un castigo sin fin,

\footnotetext{
' Sub terra. Cuadros mineros (Santiago: Imprenta Moderna, 1904). La colección contenía: "Los inválidos", "La compuerta número 12", "El grisú", "El pago", "El chiflón del diablo", "El pozo", "Juan Fariña" y "Caza mayor". A la segunda edición, que trae una introducción de Armando Donoso (Santiago: Editorial Chilena, 1917), se agregaron: "El registro", "La barrena", "Era él solo", "La mano pegada" y "Cañuela y Petaca".

${ }^{2}$ Alberto Blest Gana, Los trasplantados, 2 tomos (París: Garnier Hermanos, Libreros-editores, 1904). Al año siguiente apareció en Santiago como folletín del diario El ferrocarril. Por aquella misma casa editorial hay una segunda edición en 1911, idéntica a la primera. En este artículo las citas se harán según la $4^{\mathrm{a}}$ edición: Santiago de Chile: Zig-Zag, 1974.
} 
como a un infierno. En efecto, además de ciertos lóbregos capataces, es el diablo quien pareciera controlar ese espacio: los dos cuentos más conocidos de la colección, "La compuerta número 12" y "El chiflón del Diablo", se organizan en torno a la imagen del descenso a los infiernos, el primero, y en torno al poder del demonio, el segundo. El creer que el diablo habita las cavernas de las minas hasta lleva a los obreros a identificar la presencia del temido ciego Juan Fariña - personaje que da título al penúltimo de los relatos - con una suerte de personificación humana del dios del mal.

Al publicar esta colección Lillo alcanza una cima creativa en el país: es el libro de horror más pausado y penetrante y acaso el más fuerte escrito en Chile hasta entonces. Todos sus cuentos tienen un remate desolador en que se impone la muerte o el sufrimiento abierto en las peores heridas que se podían hacer en contra de la justicia o de la dignidad humanas. Indudablemente la obra porta la marca temática y las señas de la disciplina formal enseñadas por Émile Zola al novelar el asunto de las vidas desoladas de los mineros del norte de Francia en su clásica Germinal, aparecida en París en 1885 y traducida al castellano desde ese mismo año. ${ }^{3}$

Es del todo comprensible que en 1904 Lillo permanezca fiel al naturalismo enseñado por Zola: cuanto ocurría a las clases trabajadoras en Chile y en el resto de la América Latina por entonces iba a proveer de materiales directos e inspiración a un par de generaciones de escritores hasta bien avanzado el siglo; en este sentido, Lillo es más bien un adelantado de esa concepción de escritura que postulaba el texto literario como un espacio para una denuncia o una tesis social expresadas estéticamente.

Bien distinto es el caso de Blest Gana, quien por estos años ya está detrás de un tipo de novela cosmopolita, más centrada en el conflicto humano (se podría decir presicológico) que no ha sido necesariamente generado por una situación de pobreza o injusticia social, Émile Zola tenía poco que enseñarle a esta altura de su carrera literaria; sin embargo no dejan de leerse algunas señas de las enseñanzas de su escuela, en especial en el diseño del personaje Ignacio Sagraves, el expatriado pobre y desesperado quien no encuentra más solución que el suicidio. ${ }^{4}$

Pero, en general, los hispanoamericanos que Blest Gana representa en su obra son la versión opuesta de los mineros del carbón. En Lillo se trata de una creación literaria pro-

\footnotetext{
${ }^{3}$ Germinal tiene una versión castellana por Luque, en Madrid: Imprenta de A. Pérez, 1885. En otro lugar nos hemos ocupado de la relación entre la obra de Lillo y la de Émile Zola: "Secuencias paralelas en 'La compuerta número 12', de Baldomero Lillo", Revista Chilena de Literatura 31 (1988) 63-79.

${ }^{4}$ En un pasaje de la novela relativo a este personaje que sirve de mensajero al padre de los Canalejas, se compara su asfixiante pobreza con el estado desesperado de la vida de los mineros subterráneos: "Confusamente, como una lejana luz de incendio, la protesta de los desheredados del destino ardió en su pecho. La imprecación de ira contra las desigualdades de la suerte, la que levanta las utopías del comunismo, que ha cargado más tarde las bombas de los anarquistas, hizo resonar en su pecho la enconada letanía de la incurable miseria. Pero aquello fue como el suspiro de los que trabajan en las minas, allá en lo hondo y lo oscuro, envidiando el aire y la luz de los que reciben los rayos del sol. ¡A qué lamentarse! ¡A qué aspirar lo imposible!” (53-54). Es posible pensar que el párrafo anterior sea una alusión del narrador de Blest Gana apuntada en contra de las injusticias en las que se basa la inmensa riqueza que unos malgastan mientras otros padecen.
} 
proletaria: escrita con la conciencia guía de contribuir a develar la existencia de grupos laborales que en el país vivían marginados y explotados. Lillo ha aprendido el aspecto político de la narrativa consagrada por Zola; además, históricamente, al escribir participa de una época que bien pronto iba a conocer de la rebelión de los oprimidos chilenos y de las horrendas formas de represión a las que quedaban expuestos. El país era gobernado por una oligarquía autocomplaciente y en absoluto preparada para responder a las nuevas demandas sociales. El presidente de la república entonces, Germán Riesco (1901-1906), respondería a las justas peticiones de aquellos grupos obreros de la misma manera que se lee en los cuentos de Lillo -especialmente en "El grisú" - es decir, con la represión y el castigo más desaforados. Esta tendencia de los líderes conservadores a las masacres populares alcanzó un punto trágicamente alto un par de años después, en diciembre de 1907, cuando en la escuela Domingo Santa María de Iquique fueron acribillados varios miles de trabajadores del salitre que solicitaban un aumento de sus miserables salarios. ${ }^{5}$

Por supuesto que la obra de Alberto Blest Gana no tiene intenciones reivindicativas de aquel tipo. Su voluntad constructiva se enfoca hacia las clases altas y sus modos de vida, aun cuando sus personajes más meritorios continúen siendo miembros de los grupos medios instruidos - Patricio Fuentealba, en Los trasplantados quien, como Martín Rivas, ama a una joven de posición económica mucho más elevada que la suya, razón por la cual la familia de ella lo rechaza. Blest Gana tampoco tiene aspiraciones de transformarse en vocero de ninguno de tales grupos; cuando más se le sospecha escribiendo en defensa de ciertos intereses personales. En efecto, poco apreciado por el grupo que rodea a José Manuel Balmaceda - y especialmente por un hermano de éste, José Ezequiel - luego de asumir aquel el cargo presidencial el 18 de septiembre de 1886, comienzan presiones para destituirlo. Blest Gana, herido sobre todo por la acusación que se le hace de haberse "deschilenizado" - debido a tantos años fuera del país - presenta su protesta y su renuncia en marzo de 1887.6

\footnotetext{
${ }^{5}$ Un historiador del presente escribe refiriéndose a las represiones de los movimientos masivos: "El primero de ellos fue la gran huelga de Tarapacá en 1890, en protesta contra el sistema de pago mediante vales y fichas. En dicha ocasión paralizaron los operarios de las salitreras y los lancheros y jornaleros de Iquique; este paro terminó con serios incidentes en las oficinas Ramírez, Rosario y Tres Marías, además del incendio de la oficina de San Donato. En 1903 el país fue sacudido por la huelga de los trabajadores portuarios que exigían mejores salarios que, al serles negados, generaron graves enfrentamientos con las fuerzas policiales y la consecuente muerte de 50 trabajadores y más de 200 heridos. En 1905, en Santiago, una manifestación popular destinada a conseguir mejores precios de la carne, entre otros, degeneró en una colosal asonada que mantuvo a la ciudad de Santiago en aflictiva situación por más de tres días. En 1907 Iquique fue el escenario también de una trágica represión militar, cuando por razones salariales paralizaron más de 30.000 trabajadores de las salitreras. Unos 15.000 operarios se dirigieron al puerto de Iquique para conseguir que las autoridades mediaran en el conflicto. A ellos se sumaron gremios de dicha ciudad, la que se vio paralizada y luego declarada en estado de sitio. La intervención represiva de las fuerzas militares contra los obreros alojados en la Escuela Santa María dejó un saldo de aproximadamente 2.000 víctimas fatales". Gonzalo Izquierdo, Historia de Chile III (Santiago: Editorial Andrés Bello, 1990) 113-114.

${ }^{6}$ Por esa fecha Blest Gana escribió a Balmaceda una carta donde se incluye el siguiente párrafo: "En cuanto a que un hombre se desnacionalice porque reside muchos años fuera de Chile, usted me permitirá que no considere el cargo como apoyado en ningún fundamento sólido. Acaso podría
} 
Lo han enemistado con el nuevo gobierno de Chile, y ha sido uno de esos que vive en París "por puro gusto" quien lo ha mal informado con los Balmaceda, alguien que quería ocupar su cargo; al parecer, uno de los Cousiño Goyenechea. Estos influyentes seis hermanos eran hijos del multimillonario Luis Cousiño, quien hizo de sus minerales carboníferos de Lota una gran empresa, y de Isidora Goyenechea de Cousiño, propietaria de minas de plata en Copiapó, de las haciendas Macul y El Marco, en Santiago y Melipilla respectivamente, y de la mitad del centro de Valparaíso. La singular familia residía en París, empeñada en rozarse y convivir con lo mejor de aquella ciudad deslumbrante. ${ }^{7} \mathrm{El}$ peso chileno tenía entonces prácticamente paridad con el dólar y el franco francés.

Desde su aparición en París Los trasplantados fue esperada en Santiago con curiosidad, literaria y social; literaria, porque el autor continuaba encabezando la narrativa nacional; social, sobre todo para descifrar las claves acerca de los chilenos que Blest Gana se había encargado de trasladar a su obra. El autor ha cambiado, como ya era usual en sus obras, los nombres que permitieran una fácil y comprometedora identificación. En la novela la familia chilena que derrocha en París es la encabezada por Graciano Canalejas y Quiteria Gordanera, quienes, por lo demás, llevan las mismas iniciales de los Cousiño Goyenechea. Sin embargo, el relato no llega al extremo de afirmar que la fortuna de los Canalejas Gordanera proviene del carbón; se dice que su inmensa riqueza se genera en sus propiedades agrícolas y en el comercio, cosa que también es cierta en el caso de aquella familia no ficticia. Hay un pasaje en la novela en el cual uno de los Canalejas Gordanera expresa su deseo de ver a su padre ocupando el cargo de embajador en París y esto, cuando hacen preparativos para recibir a los familiares de un príncipe europeo que ha solicitado la mano de la muy bella Mercedes Canalejas:

Papá, te has conducido como un gran diplomático - exclamó Milagritos.

Dolorcitas repitió el cumplido al que hizo eco la voz apagada de Juan Gregorio:

¡Toma! ¡Es una buena idea! Nuestro gobierno debería nombrar a papá ministro en París, y a mí su secretario. Así iríamos de uniforme a recibir a las princesas a la estación. Yo "retengo" desde ahora a la princesa Thyra para darle el brazo. ¿Quién sabe si no le doy en el ojo! (184).

decirse eso del que se mantiene muchos años alejado del suelo natal por puro gusto. Mas no es posible formular semejante acusación contra el que vive ocupado del servicio de su patria; que sigue con vivísimo interés su desarrollo; que le consagra todos sus instantes y que pone su grano de arena con infatigable celo en esa obra común de engrandecimiento nacional, que no puede ser completa si no tiene representantes activos y experimentados, repito 'experimentados"'. Trozo citado por Raúl Silva Castro en su Alberto Blest Gana (1830-1920). Estudio biográfico y crítico (Santiago: Imprenta Universitaria, 1941) 279.

${ }^{7}$ Luis Cousiño, nacido en Santiago en 1835, era hijo del legendario Matías Cousiño, fundador de los minerales de Lota, que compró después de hacer fortuna en las minas de Atacama. Matías Cousiño comenzó la explotación del carbón hacia 1849 y luego fue diputado y senador, desde Manuel Montt en adelante. Falleció en 1863. Isidora Goyenechea Gallo fue prima de Pedro León Gallo, caudillo de la revolución constituyente de Atacama y sobrina de Candelaria Goyenechea, propietaria de ricos minerales en Copiapó, principalmente el de Chañarcillo. 
También se puede pensar que el personaje Graciano Canalejas alude a Francisco Subercaseaux Vicuña, archimillonario que residió con gran lujo en París por más de veinte años, y quien tampoco ocultó empeños por conquistarse ese puesto de embajador; Luis Orrego Luco cuenta de este caballero chileno banquero, salitrero y agricultor:

Don Francisco vivía en un magnífico departamento cerca del Arco del Triunfo, con todo el lujo fastuoso de un gran señor europeo. En lo alto de la escala de mármol, en el espacioso hall con enormes tapicerías de Beauvais y sillones dorados del siglo XVIII recibía a sus invitados, en compañía de Juanita Brown, su mujer. Lacayos de calzón corto y medias de seda, tomaban los abrigos, abrían las puertas y anunciaban a los invitados (431).

Pero no se crea que se trata de un caso aislado, como este mismo memorialista agrega más adelante: "Los sudamericanos y, en especial los chilenos, gastaron fortunas en París: los Cousiño, los Errázuriz, los Urmeneta, los Ossa, y muchos otros vivían en palacios y daban grandes comidas. Paseaban en elegantes carruajes en el Bois ... Derrochaban torpe y estérilmente sus millones sin lograr nunca conocer la verdadera vida del gran mundo". 8 Resulta paradójico, cuando menos, que la fortuna que los Cousiño Goyenechea derrochan en París provenga en su mayor parte del trabajo de aquellos miles de mineros anónimos y miserables desenterrados por la pluma de Lillo, quienes luchan ferozmente en la profundidad de la tierra para extraer la riqueza que sustenta los excesos de sus propietarios. Antítesis del caballero recién descrito, el minero Pedro María — protagonista de "El pago"- habita en un solo cuarto:

Transido de frío, con las ropas pegadas a la piel penetró en el estrecho cuarto. Algunos carbones ardían en la chimenea y delante de ella, colgados de un cordel, se veían un pantalón y una blusa de lienzo, ropa que el obrero se puso sin tardanza, tirando la mojada en un rincón.. Su mujer le habló entonces, quejándose de que ese día tampoco había conseguido nada en el despacho. Pedro María no contestó, y como ella continuase explicándole que esa noche tenía que acostarse sin cenar, pues el poco café que había lo destinaba para el día siguiente ... Y rendido, con los miembros destrozados por la fatiga, fue a tenderse en un camastro arrimado a la pared. Aquel lecho compuesto de cuatro tablas sobre dos banquillos y cubierta por unos cuantos sacos, no tenía más abrigo que una manta deshilada y sucia. La mujer y los dos chicos, un rapaz de cinco años y una criatura de ocho meses, dormían en una cama parecida, pero más confortable, pues se había agregado a los sacos un jergón de paja (48).

\footnotetext{
${ }^{8}$ Se cita el trozo de la obra de Luis Orrego Luco, Memorias del tiempo viejo (Santiago: Ediciones de la Universidad de Chile, 1984) 417-418; proviene de un aparte de ese libro que Orrego titula "Los criollos en la vida social y Los trasplantados", 416-419. Allí también agrega lo siguiente: "Las grandes fortunas chilenas adquiridas en las minas por los Urmeneta y los Ossa y las que venían del carbón de Lota por los Cousino, estaban representadas en París por la belleza de algunas señoras de extraordinario encanto y elegancia: entre ellas las de Errázuriz Urmeneta, de Santiago y Ramón Ossa, de Arturo Cousino, en tanto que Carlos, su hermano, se paseaba en una espléndida victoria al lado de su querida oficial, bella actriz de un teatro de boulevard" (419).
} 
Mientras unos habitan en los infiernos, los otros residen en el cielo de las burguesías internacionales: los barrios elegantes de lo más alto de París. Hallarse allá es la máxima sensación para uno de estos criollos soterrados, así vivida en el baile que la duquesa de Vieille-Roche ofrece en honor del príncipe de Gales:

Agustín Palomares separó a Cuadrilla del grupo que formaban las dos hermanas con De Morins y Termal.

Vamos a dar una vuelta por los salones - le dijo-. Un hombre chic no debe andar al lado de su mujer, como cuidándola.

Agustín estaba radiante. Aquella atmósfera de grandeza y señorío le infundía un sentimiento de orgullo: un creerse superior a su propia esfera estimulaba su vanidad, le daba impulsos de globo descargado de su lastre, que hiende el espacio, como de salto, hacia arriba (99).

En los cuentos de Lillo la imagen del descenso a la mina como un descenso a los infiernos está guiada - como se ha notado- por un sutil paralelo con la Commedia del Dante, y con Germinal; en Blest Gana no se advierte un paradigma tradicional de ese tipo; el cielo aparece como un espacio metafórico al que se llega por vía del ascenso económico y social. El trayecto hacia tales alturas es menos explícito y se apoya más bien sobre la realidad histórica de aquellos grupos antes que en su representación literaria en la novela; el París de la gran nobleza es el espacio en el cual las burguesías periféricas sueñan residir algún día para confirmar su riqueza, elegancia y posición. Es el espacio que para ellos se sitúa en lo más alto, y por eso su desplazamiento es de ascenso continuado, hasta tratar de alcanzar un poco de la sangre de los más privilegiados. Pero el viaje hacia arriba de los trasplantados es al mismo tiempo un viaje de separación de su propio país: al ingresar en el de París pierden su suelo natal y su existencia queda en un limbo donde pasan a ser extranjeros en Europa y en Hispanoamérica. Los otros, los mineros, también son privados de una existencia normal y justa por la necesidad y el hambre, y no les queda más que vivir sub terra para mantener un mísero pasar. Descenso y ascenso: ambos grupos chilenos son dos caras de una misma moneda que se ignoran, que nunca se ven, ni se han visto - acaso sólo en las primeras novelas de José Donoso, que hicieron de esa contradicción profunda su tema central.

La patria ya no está en los proyectos de los trasplantados; está solamente el dinero que les llega de la patria distante. Cualquier excusa para no retornar les sirve, pero por su vida de molicie y por el rango social que pretenden, son incapaces de generarse ingresos en Europa; razón de su doble dependencia de los fondos que reciben de su país. En un momento de lucidez, Juan Gregorio Canadejas Gordanera (¿Carlos Cousiño Goyenechea?) expresa su posición —que parece muy cercana a la mantenida por el narrador omnisciente de la novela:

Nosotros, los trasplantados de Hispanoamérica, no tenemos otra función en este organismo de la vida parisiense que el de gastar plata ... y divertirnos, si podemos. Somos los seres sin patria. Hemos salido de nuestro país demasiado jóvenes para amarlo, y nos hemos criado en éste como extranjeros, sin penetrarlo. Somos la espuma de esta gran corriente que se ilumina con el brillo de la fiesta parisiense, y se va desvaneciendo como los 
globulillos de esa espuma, sin dejar rastro de su paso. Los trasplantados suceden a los trasplantados, sin formar parte de la vida francesa en su labor de progreso, sin asociarse a ella más que en su disipación y en sus fiestas. Inútiles aquí e inútiles para su patria, que miran con desdén (120).

En fin, si no son los Cousiño o los Subercaseaux o los Ossa o los Urmeneta, es claro que la familia novelada es un arquetipo de todos aquellos chilenos; en cualquier caso se trata de los grandes patricios, de los dueños de enormes capitales cuyos dividendos se gastaban a discreción en Europa; son los beneficiarios directos de un Estado que no imponía límites de ninguna clase al uso o abuso de la riqueza ni controles a su producción; concreción del sistema y del pensamiento plutocrático y antiprogresista que había derrotado a Balmaceda y sus "siúticos" en la tragedia nacional de 1891.

Pero es preciso aclarar que en ningún momento del amplio discurso novelesco se dice que esta familia sea chilena, ni se menciona a Chile como su país de origen. Y apenas se denuncian como tales, cuando alguna vez se refieren a los mejillones como "choros" o en un par de ocasiones cuando anteponen un artículo definido antes de un nombre propio.

Por respeto a la estructura ficcional del texto, es necesario establecer un rasgo de la novela que sitúa a Blest Gana entre los precursores del recurso de la composición geográfica simbólica en la literatura continental: el narrador de la novela habla del lugar de origen de los Canalejas como "de su fecunda tierra de Hispanoamérica" (16), o se refiere a gente venida de "distintas secciones de la América Latina" (83), pero sin individualizar ningún país, ni para los Canalejas Gordanera ni para ningún otro latinoamericano representado en la extensa novela.

Si bien Blest Gana silencia los nombres de la geografia precisa y real de sus criollos millonarios y extravagantes, hace tan explícita como inequívoca su procedencia hispanoamericana. Es interesante comprobar como la idea de un país de la América española, imaginario y sintético, surge entonces en el ambiente de la novela continental; en 1904 William Sydney Porter, más conocido por su nombre de pluma de O. Henry, da a luz su obra "Of Cabbages and Kings", la cual transcurre en la alegórica república hispanoamericana de Anchuria. ${ }^{9}$ Igualmente en 1904 Joseph Conrad publica Nostromo, célebre novela cuya acción principal transcurre en la república centroamericana de Costaguana, un más claro acronismo de Costa Rica, Nicaragua y Guatemala. Más tarde vendrá una serie de regiones alegóricas de lo continental, desde los condados y países propuestos por William Faulkner y Alejo Carpentier hasta el popularizado Macondo.

Importa menos, en todo caso, la condición geográfica que la social: mientras el mundo narrado de los mineros se postula como una cara concreta del infierno, el de los millonarios criollos se presenta como el de un ascenso al cielo de la elegancia universal. La contradicción se acrecienta aún más porque mientras para los mineros el único mundo conocido es la mina y el caserío que la rodea, de los que no hay escapatoria posible, los otros chilenos no sólo parten a París, sino que una vez allá luchan por borrar sus huellas de

\footnotetext{
${ }^{9}$ Se trata de un país tropical caribeño; al parecer Honduras, donde Porter vivió un par de años para eludir una acción judicial que lo perseguía desde sus días de cajero de un banco en Texas. Ha empleado como nombre de ese país el resultado de un juego de palabras entre los derivados de los adjetivos hondo y ancho.
} 
criollos rastacueros para asimilarse cuanto sea posible a lo europeo chic. Mientras en los cuentos de Baldomero Lillo la fuerza destructora es la necesidad más impía, en la novela de Blest Gana es el dispendio desenfrenado; mientras los mineros deben descender hacia abajo y más abajo para ganar su sustento, los trasplantados van guiados por la ley de subir a lo alto, lo más arriba posible entre el tout Paris. La madre del joven minero destinado a una segura muerte en el chiflón del Diablo, había reflexionado en ese sentido:

Siempre temerosa de una desgracia, su imaginación no se apartaba un instante de las tinieblas del manto carbonero que absorbía aquella existencia que era su único bien, el único lazo que la sujetaba a la vida.

¡Cuántas veces en esos instantes de recogimiento, había pensado, sin acertar a explicárselo, en el porqué de aquellas odiosas desigualdades humanas que condenaba a los pobres, al mayor número, a sudar sangre para sostener el fausto de la inútil existencia de unos pocos! $!^{10}$

La oposición entre ganar un dinero mínimo para sobrevivir, como ocurre a los mineros y, por el contrario, derrocharlo o tirarlo en París, como hacen los patricios, son dos constante estructurales en ambas obras; dos fuerzas temáticas divergentes pero ordenadoras de varios de los acontecimientos más relevantes de los respectivos procesos narrativos de los textos. Así en los cuentos de.Sub terra la urgencia por obtener unos centavos para derrotar el hambre se convierte en motivo omnipresente; como en Los trasplantados el gastar en lujos, fiestas y, por último, en la dote, para casar a Mercedes con el príncipe Roespingsbrück son erogaciones enormes de las que la familia espera resarcirse cuando el nuevo lazo les abra, por fin, las puertas de los salones más exclusivos de la auténtica nobleza europea.

Las ansias de aquellas familias por rozarse con personas de título les ha hecho perder toda cordura; estos expatriados sueñan con unirse a aquellas gentes que, despreciándolos, necesitan sin embargo de su dinero. En este sentido se puede leer en ambas obras una suerte de doble clímax: en los relatos de Lillo, cuando el débil niño minero es atado a la compuerta número 12, en el cuento de ese nombre, para que cumpla el sacrificio del trabajo obligatorio en el fondo de una mina de carbón en Lota; en la novela de Blest Gana, cuando Mercedes Canalejas se sacrifique en un matrimonio forzado con el príncipe Stephan de Roepingsbrück, ante el arrobamiento de su familia, el tal príncipe recibirá casi dos millones de pesos que la familia chilena ha dado como dote de Mercedes para que él acepte la unión. Millones que han salido de aquellas mismas minas de carbón, aunque el texto no lo diga. Si bien es cierto que no existían entonces medidas que impidieran a la burguesía sacar sus capitales o ganancias hacia el exterior, ni que los gravaran significativamente, tampoco había legislación social que contribuyera a impedir o limitar los abusos sufridos por los mineros, o por cualquier obrero. ${ }^{11}$

${ }^{10}$ Las citas de Sub terra. Cuadros mineros se hacen según la $7^{\mathrm{a}}$ edición (Santiago: Editorial Nascimento, 1954). La anterior, de 61-62.

11 Es recién en 1924, y ante las presiones de distintos grupos disidentes, que el presidente Arturo Alessandri accede a aprobar leyes que, entre otras medidas, fijaban una jornada laboral de ocho horas, limitaban las demandas sobre el trabajo de las mujeres y los niños, y que otorgaban algún tipo de seguro en contra de accidentes laborales. Véase Gonzalo Izquierdo, III, 22-23. 
Extendiendo la oposición entre el cuento dicho y la novela, vale situar el sentido de otro compromiso significativo: mientras en la mina se trata de colocar al niño para que ayude a aliviar el hambre de la familia, en París se trata de colocar a la joven que vive en opulencia, en una unión que ella no desea, pero que será el pasaporte social definitivo de los criollos, como le asegura la condesa De Montignan, quien representa al príncipe en las negociaciones prematrimoniales, a Graciano Canalejas: "A partir de ese momento [la boda] usted y su familia entrarían a formar parte de las personas que 'cuentan', por su importancia, en París" (178).

La ficción no irrespeta los márgenes de lo que acaecía a los criollos en París; tiende a testimoniar hechos, si no corrientes, al menos documentados por otros testigos de su momento. Así Luis Orrego Luco relata en su obra antes citada:

La colonia hispanoamericana de París tenía una admiración religiosa por los títulos como si fueran dones del cielo, gracias divinas que sólo disfrutaban algunos privilegiados y seres superiores planeando su vuelo sobre la esfera de los demás mortales. Las familias chilenas perdían el seso al oír de títulos y blasones. Los Concha Subercaseaux, los Errázuriz, Eugenia Huici y muchas otras, no hacían más que hablar de sus amistades tituladas, dándose con esto ínfulas de grandeza (417).

Pero para conseguir esos anhelados títulos las fortunas de Hispanoamérica debían competir con las venidas de los Estados Unidos, que se desvivían por la misma obsesión. En el pasaje de Los trasplantados relativo a los arreglos para la boda de Mercedes Canalejas, la condesa De Montignan -en un momento de duda de Graciano Canalejas, ante las demandas crecientes del príncipe - lo amenaza, diciéndole "que, sin su verdadera pasión por Mercedes, el príncipe habría ya consentido en oir ciertas ventajosas proposiciones que se le habían insinuado de parte de un archimillonario de Chicago. Este vendedor de puercos dotaría espléndidamente a su hija ..." (177). En otra parte la familia criolla, ofendida por esa competencia, se pregunta: “¿Por qué habían de ser solamente las yankees las únicas de la numerosa familia americana que se uniesen a grandes títulos europeos?" (194). Estos pasajes en la obra de Blest Gana sobre la irrupción del dinero yankee en las altas esferas de Europa, al tiempo que aluden a un hecho social histórico, parecen rendir homenaje a la obra narrativa de Henry James, el novelista norteamericano que había iniciado este asunto en la literatura del continente, y quien entonces aparece como uno de los maestros de Blest Gana; en efecto, en 1877 James publicó The American, historia de un comerciante de aparatos sanitarios, quien después de amasar una gran fortuna, se marcha a París donde logra casarse con una marquesa. Aun más coincidente con estas notas: en 1904 Henry James culmina el ciclo de tal tema con la publicación de The Golden Bowl, una de sus obras más conocidas - y complejas - en la cual una fina joven estadounidense se casa con un conflictivo príncipe romano.

Orrego Luco, quien vive intensamente esos años parisienses, vuelve a señalar que esa tendencia, más allá de la novela, no era ajena a los chilenos millonarios que disfrutaban de París; afirma en su obra ya citada: "Las norteamericanas dieron el ejemplo al casarse con nobles y lores arruinados, que ofrecían sus títulos en quiebra, a cambio de millones. Entre las sudamericanas, María Luisa Mac-Clure de Edwards, conquistó más tarde el título del Marqués de Cars para su encantadora hija Teresa. La perdió para siempre y alejada del 
mundo de sus mayores entró a convivir con el de su nueva familia. Recordando esta característica de los sudamericanos en Europa, entendía cada día mejor la realidad trágica de Los trasplantados" (424-425).

Pero Alberto Blest Gana en ninguna de sus novelas incluye los apellidos históricos chilenos para identidad de sus protagonistas; los disfraza de alguna manera; Alone afirma que lo hace para no herir la imagen de la verdadera aristocracia nacional. ${ }^{12}$ Sin embargo, aun bajo el recurso de un disfraz, la alusión a las grandes familias del país no puede ocultarse; son apellidos que cualquier lector reconocería los que traslucen en el ámbito del texto. En cambio los mineros de Lillo son casi siempre anónimos, cuando más un nombre de pila o un apodo, simplemente alguna mujer que sufre o alguien que es identificado sólo por la clase de trabajo que pueden hacer sus manos.

Curiosamente ese mismo año de 1904 nacía Ricardo Reyes Basoalto, quien más tarde en sus poemas, bajo el seudónimo de Pablo Neruda, iba a dar una voz definitiva en las letras hispánicas a los injustamente condenados del feudalismo entonces practicado por todo el continente. Baldomero Lillo había entregado una primera gran colaboración en esa causa, apuntado con sus cuentos en uno de los blancos de la época, desde perspectivas estéticas tanto como históricas. Además, con el contrapeso de las obras de Blest Gana, las avenidas para el cabal desarrollo de las letras chilenas quedaban perfectamente abiertas.

\footnotetext{
${ }^{12}$ Esta idea la ha expresado un par de veces; refiriéndose a Los trasplantados ha escrito: "Ricos en su tierra, no de grande estirpe -Blest Gana evita herir a la clase más alta y siempre le mezcla un poco de medio pelo- partieron a pasear a Europa y fueron quedándose, so pretexto de educar a los hijos, en realidad para deseducarlos. Creen que sus millones les abrirán todas las puertas y, al ver que por prudencia o desdén aristocrático, muchas se les resisten, ellos y ellas emprenden la batalla". Hernán Díaz Arrieta (Alone), Don Alberto Blest Gana. Biografia y crítica (Santiago: Editorial Nascimento, 1940) 200. El capítulo VIII de esta obra está dedicado a Los trasplantados.
} 